\title{
O PARADIGMA DA SUSTENTABILIDADE E A ABORDAGEM CTS: MEDIAÇÕES PARA O ENSINO DE CIÊNCIAS
}

\author{
THE SUSTAINABILITY PARADIGM AND THE STS APPROACH: MEDIATIONSFOR \\ SCIENCE EDUCATION
}

\author{
Elizandra Rêgo de Vasconcelos ${ }^{1}$ \\ Nádia Magalhães da Silva Freitas ${ }^{2}$
}

\section{RESUMO}

A sociedade tem sido confrontada com questões que envolvem as interações entre Ciência, Tecnologia e Sociedade (CTS), as quais revelam implicações sociais, econômicas, ambientais, éticas, entre outras. E o paradigma da sustentabilidade ocupa posição destacada nesse âmbito. Entendemos que as orientações CTS constituem importante instrumento para a edificação da noção de sustentabilidade, no campo do ensino de ciências, cuja perspectiva insere-se na formação de cidadãos com sensibilidade socioambiental - cidadãos que possam analisar e avaliar criticamente as questões relacionadas aos campos social, ambiental, econômico, entre outros. Propomo-nos, neste artigo, a discutir as articulações possíveis entre o paradigma da sustentabilidade, o enfoque CTS e o processo de ensino e de aprendizagem em ciências.Essa articulação, certamente, contribui para pensar as implicações do atual modelo de desenvolvimento e as relações CTS inseridas, por exemplo, em vários temas, contextos, dimensões, saberes e estratégias de ensino. Certamente, temos que empreender esforços no sentido de aproximar o campo natural e o campo social, na apreensão da complexa realidade que hoje se apresenta.

Palavras-chave: Ensino de Ciências. Sustentabilidade. CTS.

\begin{abstract}
The societyhasbeen confronted withissuesthat involve interactionsbetweenScience, Technology andSociety (STS), which revealsocial,economic, environmental, ethical implications, among others. The sustainability paradigmoccupiesa prominent positionin this area. We understand that the STS guidelinesare an importantinstrumentfor buildingthe concept ofsustainabilityin science education, whose perspectiveis consistent with theformation ofcitizenswithenvironmentalsensitivity-citizens
\end{abstract}

\footnotetext{
${ }^{1}$ Doutoranda do Programa de Pós-Graduação em Educação Científica e Tecnológica (PPGECT), da Universidade Federal de Santa Catarina (UFSC), e-mail: elizandravasconcelos@ hotmail.com, membro do Grupo de Pesquisa de Discursos sobre Ciência e Tecnologia (DICITE). Professora pelo Plano Nacional de Formação de Professores (PARFOR), do Curso de Licenciatura em Ciências Naturais, da Universidade Federal Rural da Amazônia (UFRA).

${ }^{2}$ Doutora em Desenvolvimento Sustentável pelo Núcleo de Altos Estudos Amazônicos (NAEA), da Universidade Federal do Pará (UFPA). Professora Associada I, do Programa de Pós-Graduação em Educação em Ciências e Matemáticas (PPGECM), do Instituto de Educação Matemática e Científica (IEMCI), da UFPA, e-mail: nadiamsf@yahoo.com.br
}

AMAZÔNIA - Revista de Educação em Ciências e Matemáticas V.9 - no 17 - jul. 2012/dez. 2012, p.89-108. 
who are able to analyze andevaluate criticallyissues relatedtothe social,environmental and economic field, among other aspects. We propose,in this article, to discuss thepossible links betweenthe sustainability paradigm, the STS approachand the process ofteaching andlearningin science. This articulationcertainlyhelps tothink the implications of thecurrent development modeland the relationships STS, inserted, for example, onvarious issues, contexts, dimensions, knowledge and teaching strategies. Certainly, we mustundertakethe effort to approximate thenaturalandsocialfields, in the apprehension of the complex reality as it stands nowadays

Keywords: Science Teaching.Sustainability.STS

\section{INTRODUÇÃO}

A sustentabilidade do planeta é pauta de discussões em vários campos societários, certamente, em virtude das relações estabelecidas entre o ser humano e a natureza, notadamente no que diz respeito ao consumo, à exploração e à alteração de ambientes e sistemas naturais.Esse estado de coisa caracteriza a chamada crise ambiental, cujas dimensões e escopo levam a considerar a existência de uma crise civilizatória (LEFF, 2002). Apoiando a ideia, Bigliard e Cruz (2007, p. 128) observam que a“[...] sociedade atual, caracterizada pelo modo de vida capitalista, e orientada para o consumo, vem tratando os recursos naturais como fonte de matéria-prima para seu consumo e entendendo o ambiente natural como depósito para seus resíduos”. Em verdade, essa crise está vinculada às bases históricas da evolução das sociedades, precisamente quando da adoção do modelo de produção capitalista.

Os eventos que conformam a crise ambiental têm relação intrínseca com o entendimento de que a ciência e a tecnologia são,no conjunto, força motriz para o progresso e desenvolvimento, sem que, entretanto, considerem-se suas implicações sociais, ambientais, culturais, políticas e éticas (BAZZO, 2010). Por sua vez, as relações entre Ciência, Tecnologia e Sociedade (CTS) são alvo de muitas pesquisas no âmbito da educação em ciências. Em linhas gerais, o enfoque CTS pretende a construção de conhecimentos que estejam associados a pensamentos e a atitudes que tenham por foco fundamental a compreensão das implicações concernentes as interações que se estabelecem entre ciência e tecnologia no meio social (AULER, 2002; PINHEIRO; SILVEIRA; BAZZO, 2007). 
Assim, compreendemos que o enfoque CTS, no processo de ensino de ciências, precisa propiciar reflexões e discussõesacerca de

[...] uma imagem de ciência e de tecnologia que possa trazer àtona a dimensão social do desenvolvimento científico-tecnológico, entendido como umproduto resultante de fatores culturais, políticos e econômicos. Deve ser analisado seucontexto histórico e considerado como uma realidade cultural que contribui de forma decisivanas mudanças sociais, cujas manifestações se expressam na relação do homem consigomesmo e com os outros. Tal contexto, resultante de uma construção histórica, carregado decontrovérsias e negociações, precisa ser assim compreendido, para que possa garantir a participação pública e democrática dos cidadãos nas decisões (PINHEIRO; SILVEIRA; BAZZO, 2009, p. 2).

Nesses termos, entendemos que as orientações CTS constituem importante instrumento para a edificação da noção de sustentabilidade, no campo do ensino de ciências, cuja perspectiva insere-se na formação de cidadãos com sensibilidade para as questões sociais, ambientais, econômicas, culturais, entre outras, que cotidianamente a sociedade enfrenta. E, certamente, precisa de cidadãos que possam criticamente avaliar para,então, proceder à tomada de decisão quando solicitados.

Nesse ponto, temos a acrescentar que a ênfase dedicada à construção da noção de sustentabilidade, na nossa concepção, é justificada por três argumentos, quais sejam: 1) o momento socioambiental atual é tenso, quando se considera os limites do planeta; 2) a tecnologia, produto do conhecimento científico, parece não ter sido construída em vinculação a uma ética que indique o sentido e os limites de sua difusão e aplicação no meio social; 3) a educação científica passou por um período de "cegueira" em relação às consequências que o uso do conhecimento científico poderia ocasionar à sociedade, em virtude do obscurantismo técnico $^{3}$, fomentado pelo cartesianismo. Sendo assim, a reflexão e a construção da noção de sustentabilidade tornam-se essencial para o ensino de ciências no século XXI (SACHS, 2008; VEIGA, 2005).

Nesse sentido, o objetivo deste artigo é discutir as articulações possíveis entre o paradigma da sustentabilidade, o enfoque CTS e o processo de ensino e de aprendizagem em ciências, tendo em vista um futuro presumível e sustentável na Terra. Para isso, recorremos ao estudo eà análise de vários recortes bibliográficos sobre educação científica e sustentabilidade. Desse modo, acreditamos poder contribuir para algumas reflexões úteis para o ensino de ciências, articuladas ao pressuposto da sustentabilidade do planeta.

\section{ENFOQUE CTS E O ENSINO DE CIÊNCIAS}

\footnotetext{
${ }^{3}$ Compreendemos, por obscurantismo técnico, o estado de ignorância e passividade teórica e intelectual ocasionada pela crença cega no conhecimento técnico-científico.
} 
Inicialmente, a percepção das relações entre Ciência e Tecnologia (C\&T)restringia-se ao pensamento de que a combinação de ambas só acrescentaria benefícios à sociedade. Essa convicção deve-se, por um lado, à compreensão da ciência como neutra e objetiva, ou seja, uma instituição autônoma, regida por si própria e sem qualquer relação com o meio social. E, de outro lado, ao entendimento da tecnologia como sinônima de supremacia, desenvolvimento e dominação socioeconômica (PINHEIRO; SILVEIRA; BAZZO, 2009; SHOR, 2007).

Entretanto, as últimas décadas serviram para ratificar que a ciência “[...] longe de ser autônoma, estaria presa as suas estruturas sociais de determinação" (SHOR, 2007, p. 338). Por isso, autores como Bazzo (2009),Shor(2007), Delizoicov, Angoti e Pernanbuco (2009)entendem que o ensino de ciências precisa ser contextualizado socialmente. Desse modo, em meados de 1960, alguns eventos constituíram-se verdadeiros indícios deque confiar excessivamente e exclusivamente nos benefícios da relação C\&T importa em conduta temerária. Nesse sentido, temos as seguintes ponderações de Silveira e Bazzo (2009. p. 686):

\begin{abstract}
O projeto Manhattan [projeto para o desenvolvimento da bomba atômica]e sua aplicação em Hiroshima, além de outros casos de desenvolvimentos tecnológicos vinculados à guerra e utilização militar [...] representaram o primeiro ponto de inflexão da concepção otimista do caráter benfeitor da ciência-tecnologia, junto com as preocupações dos problemas ambientais.
\end{abstract}

Esses fatos, associados à divulgação de vários casos de impactos ambientais relacionados ao desenvolvimento tecnológico e à revolução industrial, colocaram em alerta toda a sociedade. Um marco para as tessituras da problemática ambiental, nesse contexto, foi a publicação do livro "Primavera silenciosa", de Rachel Carson, em 1962 (CARSON, 2010). Segundo Wilson(2010, p. 250), “[...]Primaverasilenciosaaplicouumchoquegalvânico na consciência pública e, como resultado, infundiu ao movimento ambientalista uma nova substância e significado”. Para Lear (2010, p. 11),o “[...] livro de Carson deu início a uma transformação na relação entre os seres humanos e o mundonatural, e incitou o despertar da consciência pública ambiental". Também, a publicação da obra A Estrutura das Revoluções Científicas, de Thomas Kuhn, em 1962, provocou novo direcionamento às discussões acadêmicas sobre C\&T, enfatizando, então, o aspecto social(KUHN, 2010).

Assim, formou-se no âmbito da educação científica uma iniciativa conhecida como movimento Ciência, Tecnologia e Sociedade (CTS). Esse movimento surgiu em meio à crítica do modelo de desenvolvimento pautado, quase exclusivamente na perspectiva capitalista. Precisamente, em relação ao seu forte impacto ambiental. Também é fruto de reflexões sobre o papel da ciência e da tecnologia no âmbito da sociedade. É, na década de 1970, com a 
emergência dos problemas ambientais, que a educação científica passa a incorporar ideias do movimento CTS, em uma perspectiva de formação para a cidadania (SANTOS, 2011). O movimento CTS se caracteriza como

[..] um campo de trabalho de caráter crítico com relação à tradicional imagem essencialista da ciência e da tecnologia, e de caráter interdisciplinar para o qual concorrem disciplinas como a filosofia da ciência e da tecnologia, a sociologia do conhecimento científico, a teoria da educação e a economia da mudança tecnológica (LINSINGEN, 2007, p. 3).

Em verdade, os propósitos de CTS estão relacionados à problematização do mito da superioridade dos modos de decisões tecnocráticas, da perspectiva salvacionista da ciência e da tecnologia, do determinismo tecnológico, da compreensão de que existem construções subjacentes à produção do conhecimento científico e tecnológico, o que, em última instância, representa uma análise crítica ao modelo de desenvolvimento vigente (AULER; DELIZOICOV, 2001). Nesse ponto, cabe referir que Vilches, Gil Pérez e Praia (2011) adotam a denominação CTSA (Ciência-Tecnologia-Sociedade-Ambiente), com o propósito de destacar a perspectiva ambiental e o pressuposto da sustentabilidade, o que nos acena para o compromisso do movimento com a Educação para o Desenvolvimento Sustentável (EDS).

Nessa perspectiva, as discussões evoluíram, no campo educacional, no sentido de uma formação que vá além da "capacitação" profissional de professores e estudantes, mas que abranja a dimensão ética e cidadã, e culmine na busca pela participação dos sujeitos. Trata-se de fomentar "[...] a busca de participação, de democratização nas decisões em temas/problemas sociais que envolvam ciência-tecnologia [...] (MUENCHEN; AULER, 2007. p. 422).A contextualização social da ciência, nesse âmbito, constitui-se fator determinante para o alcance dos novos/renovados objetivos da educação científica.

De acordo com Cassiani e Linsingen (2009), as relações CTS envolvem o conhecimento científico de modo que este seja abordado segundo sua esfera política, econômica e socioambiental. Isso com a finalidade de que o conhecimento seja discutido a partir de um contexto, e não isoladamente, como se tornou comum na prática didática realizada por muitos professores, conforme o método tradicional de ensino ${ }^{4}$. Sendo assim, o enfoque CTS, no ensino de ciências, também significa mudança na maneira como professores e estudantes interagem com o conhecimento. Deste modo,

Educar, numa perspectiva CTS é, fundamentalmente, possibilitar uma formação para maior inserção social das pessoas no sentido de se tornarem aptas a participar

\footnotetext{
${ }^{4}$ Entendemos como método tradicional de ensino aquele fundamentado na memorização de conceitos e fórmulas científicas, geralmente restrito a informações livrescas e sem relação aparente com os acontecimentos cotidianos locais.
} 
dos processos de tomadas de decisões conscientes e negociadas em assuntos que envolvam ciência e tecnologia. Em outras palavras, é favorecer um ensino de/sobre ciência e tecnologia que vise à formação de indivíduos com a perspectiva de se tornarem cônscios de seus papéis como participantes ativos da transformação da sociedade em que vivem. (CASSIANI; LINSINGEN, 2009, p. 135).

Em verdade, essa preocupação em favorecer aos sujeitos uma faculdade da razão que os permitam perceber seus próprios atos em relação ao conhecimento construído e as consequências destes sobre o ambiente em que vivem é o ponto em que se intersectam as noções de sustentabilidade e as orientações CTS.

Silveira e Bazzo (2009, p. 685) destacam que o ensino de uma ciência descontextualizada socialmente contribuiu (e ainda contribui) para a continuidade de uma concepção ingênua sobre a ciência, descrita, essencialmente, como uma "[...] concepção essencialista e triunfalista, na qual se presume que mais ciência produz mais tecnologia que gera mais riqueza e, consequentemente, mais bem-estar social”. Entretanto, esse raciocínio já foi superado teoricamente tanto no âmbito da própria educação científica quanto pelas teorias econômicas nos moldes do desenvolvimento sustentável (SACHS, 2008).

Para Shor (2007), a crença cega nos benefícios que a ciência e a tecnologia poderiam acrescentar à sociedade está relacionada à "força" presente nas explicações científicas que acabam influenciando fortemente as relações sociais. Nessa lógica, a autora defende que as explicações científicas proporcionaram e fundamentaram o desenvolvimento tecnológico. $\mathrm{E}$ esse último, por sua vez, tornou-se a principal base do desenvolvimento econômico mundial, mas também ocasionou várias implicações socioambientais. Podemos citar que são vários os

[...] desastres vinculados ao desenvolvimento científico-tecnológico: vazamentos de resíduos poluentes, acidentes nucleares em reatores civis e de transportes militares, envenenamentos por produtos farmacêuticos, derramamentos de petróleo etc., que serviram para confirmar a necessidade de se revisar a política científico-tecnológica (SILVEIRA; BAZZO, 2009. p. 685).

Apreendemos que as adversidades socioambientais geradas por uma visão de ciência ingênua e reducionista levam a humanidade a produzir tecnologias que nem sempre visam àqualidade de vida. E, opostamente, muitas vezes, pretende tão somente o progresso tecnológico a serviço do mercado que gera, nessa condição, exclusão, miséria, entre outros resultados. Assim, se o desenvolvimento tem por sustentáculo a tecnologia, que não existe e nem evoluí sem o conhecimento científico, é impossível pensar qualquer transformação socioambiental apartados destas três esferas.

Nesses termos, ciência e tecnologia precisam ser estudadas a partir da reflexão sobre os vários problemas que podem ocasionar no contexto socioambiental geral (PINHEIRO; 
SILVEIRA; BAZZO, 2007). Diante desse cenário, Vieira e Vieira (2005) defendem que a perspectiva CTS torna-se eminente no âmbito do ensino de ciências, por dois motivos: (1) a velocidade com que se produzem revoluções científicas e (2) a capacidade com que a ciência e a tecnologia incidem sobre uma atitude cidadã responsável. Portanto, ensinar uma ciência de verdades absolutas configura-se inviável e cada vez mais difícil. E, o mesmo acontece com as tentativas de obscurecer as relações cada vez mais evidentes entre ciência, tecnologia, sociedade e sustentabilidade - da vida e do planeta.

Em nossa compreensão, a abordagem de conhecimentos científicos dentro de um contexto bem esclarecido e com uma finalidade social colabora para que o ensino e a aprendizagem em ciências não sejam assépticos. É nesse pensar que a formação científica realizada em nosso tempo de vida pretende viabilizar algumas condições para que as gerações futuras tenham a chance de conhecer, compreender e interagir com um mundo semelhante ao que nós habitamos nos dias atuais. E isso se coaduna com noção, até agora construída, de sustentabilidade. Ademais,

\begin{abstract}
Para que o desenvolvimento científico e tecnológico seja menos excludente, é necessário que se levem em conta os reais problemas da população, os riscos técnico-produtivos e a mudança social. Por isso, faz-se necessário ter uma visão interativa e contextualizada das relações entre ciência, tecnologia, inovação e sociedade e, muito especialmente, das políticas públicas mais adequadas para se gestionarem as oportunidades e perigos que envolvem uma mudança técnica. Ou seja, a questão não é tanto se a ciência é boa ou não, mas sim se pode melhorar e como (SILVEIRA; BAZZO,2009, p. 686).
\end{abstract}

A pesquisa de Silveira e Bazzo(2009), sobre as concepções que as pessoas envolvidas com o processo de desenvolvimento de inovações tecnológicas dentro de Incubadoras de Empresas de Base Tecnológica do Paraná possuíam sobre ciência, tecnologia, inovação e suas relações com o contexto social, revelou que a maioria dos sujeitos investigados ainda acredita que o progresso científico e tecnológico funciona como uma alavanca para o desenvolvimento econômico. Esse resultado pode estar associado ao rigor e à autoridade outorgada à ciência e à tecnologia como geradoras de maior qualidade de vida social, mediada pelo desenvolvimento técnico/industrial, de mercado e econômico. Certamente, essa construção está ainda relacionada ao mote, tão propalado durante a revolução industrial, qual seja: é preciso fazer crescer o bolo para depois distribuí-lo (VEIGA, 2005). Os processos e os problemas desencadeados por esse modo de pensar já demonstraram sua falência.

Afinal,

É indiscutível que a inovação tecnológica é necessária, seja do ponto de vista da sociedade como um todo, que precisa dela para melhorar a sua qualidade de vida e do meio ambiente, ou do ponto de vista das empresas/indústrias, que precisam 
sobreviver no mercado, tendo também lucro. A questão é: será que a inovação tecnológica precisa ser um mal, para ser lucrativa? Será que uma formação diferenciada dos geradores de tecnologia (engenheiros, tecnólogos), que promova uma mudança de visão desses profissionais, não seria o caminho para abrandar esse mal? (SILVEIRA; BAZZO, 2009, p.688).

Em verdade, quando se levanta a questão sobre uma formação diferenciada e direcionada para a construção de um novo olhar sobre a tecnologia, a qualidade de vida e o meio ambiente, já há indicativos da necessidade de discutir os três pilares da sustentabilidade, de um modo geral, quais sejam: justiça social, eficiência econômica e equilíbrio ambiental, nos termos de Sachs (2008) e Veiga (2005). Portanto, compreendemos que o estudo realizado por Silveira e Bazzo (2007) já enseja algumas articulações entre CTS e sustentabilidade.

Diante disso, é evidente a necessidade de um processo de alfabetização sociocientífica sobre temas que se inserem nas relações entre CTS e sustentabilidade. Esse processo diz respeito à interlocução e à compreensão de informações e conhecimentos que envolvam temáticas das áreas de ciências naturais,articuladas a discussões realizadas no âmbito das ciências sociais (filosofia, sociologia, antropologia, economia etc.), de modo que nos auxiliem a compreender e a interpretar a realidade ambiente, na perspectiva da sustentabilidade, entendida como multidimensional, a partir de um olhar fundamentado cientificamente e humanizado, em um contexto próximo, circundante.

\section{A EMERGÊNCIA DO PARADIGMA DA SUSTENTABILIDADE}

A noção de sustentabilidade é amplamente discutida desde a Conferência das Nações Unidas sobre Desenvolvimento e Ambiente,ocorrida em 1992. Essas discussões estão intrinsecamente ligadas às problemáticas geradas pelo processo de crescimento econômico que tem impactado o meio socioambiental, de tal maneira que a existência futura do planeta tem sido questionada. Assim, a sustentabilidade tornou-se foco em todas as esferas sociais, inclusive, a educativa (BARBIERI et al, 2010).

Nesse contexto, a Conferênciadas Nações Unidas sobre o Meio Ambiente e o Desenvolvimento (CNUMAD), ocorrida no Rio de Janeiro, em 1992, conhecida também como a ECO92,foi um marco histórico que sinalizou o momento em que a sociedade geral passou a examinar com mais zelo e preocupação os estilos de vida vigentes, notadamente, no âmbito de seus limites e consequenciaspara o meio ambiente. $\mathrm{O}$ evento polêmico trouxe à 
tona discussões acerca do desenvolvimento, sobretudo nos campos político, tecnológico, ambiental, social e educacional. E, além disso, relembrou e analisou alguns pontos que já haviam sido apontados em Estolcomo ${ }^{5}$, como, por exemplo, a necessidade do desenvolvimento de tecnologias menos agressivasà natureza (LOUREIRO, 2009).

Inicialmente, a ideia de sustentabilidade teve seu foco centrado em questões ecologistas6.. Segundo Jatobá, Cidade e Vargas (2009), a visão ecologista surge em um contexto socioambiental complicado, precisamente na segunda metade do século XX. Nesse período, ocorreu a consolidação do fordismo7, cujo ápice se deu no período posterior à Segunda Guerra Mundial, nas décadas de 1950 e 1960. Essas décadas foram designadas, no contexto capitalista, como "Os Anos Dourados" - o mundo estava envolvido pelos excelentes resultados do crescimento econômico; difundiram-se, então, grandes esperanças de crescimento baseadas na produção e no consumo em massa, os quais requeriam um intenso uso de petróleo e da eletricidade (VEIGA, 2005). Sobre isso, Zanetti, Sá e Almeida (2009, p. 175) admitem que nessa lógica,

Os avanços produtivos [...] [foram] preferencialmente direcionados [e evoluíram] para os produtos de consumo rápido e para a produção generalizada do desperdício [...]. Os avanços na produtividade, que alteram o padrão de consumo e a utilização dos bens e dos instrumentos que os produzem, são considerados a priori bons edesejáveis. Por outro lado, as suas implicações negativas são vistas como inevitáveis, consideradas como intrínsecas ao desenvolvimento do capital.

Essa mentalidade causou grande impacto social, à medida que modificou o modo de utilização dos recursos naturais pela humanidade. E isso resultou, e tem resultado, em efeitos ambientais desastrosos, os quais têm sido discutido, contundentemente, nos dias atuais.Apesar de focalizar apenas uma dimensão, em detrimento de tantas outras, a fase ecologista da noção de sustentabilidade deixou contribuições relevantes. Os autores Jatobá, Cidade e Vargas (2009, p. 53) afirmam o seguinte:

Na década de 1970, a visão ecológica começa a setraduzir em ações governamentais mais efetivas. Nos EUA, foram promulgadas as leis ambientais básicas para o controle da poluição do ar e da água [...] foi criada a Agência de Proteção Ambiental Norte-americana (EPA). Outros países adotam medidas semelhantes. No Brasil, em 1973, foi criada a Secretaria Especial de Meio Ambiente (Sema), reflexo

\footnotetext{
${ }^{5}$ Conferência das Nações Unidas sobre Meio Ambiente Humano, realizada em Estocolmo, em 1972. A Conferência de Estolcomo (1972) buscou estabelecer mecanismos de transferência de tecnologias não-poluentes aos países subdesenvolvidos, e examinar as estratégias nacionais e internacionais para incorporação de critérios ambientais ao processo de desenvolvimento.

${ }^{6}$ São aquelas relacionadas a uma percepção "preservacionista" da problemática do ambiente.Esta focaliza os desequilíbrios naturais causados pela ação humana que comprometem as condições de existência da própria espécie humana, logo, qualquer interferência humana na natureza é negativa.

${ }^{7}$ Termo referente aos sistemas de produção em massa e gestão, estes, idealizados pelo empresário, do ramo automobilístico, Henry Ford.
} 
dos compromissos internacionais assumidos, em 1972, na Conferência das Nações Unidas sobre Meio Ambiente, em Estocolmo, que difundiu os resultados da reunião do Clube de Roma e do Relatório Meadows, denominado "Os limites do Crescimento".

Certamente, essa legitimação da insatisfação da sociedade civil com os riscos ambientais, causados pelos processos de crescimento, foi historicamente importante. Todavia, recentemente, a humanidade percebeu outras dimensões igualmente relevantes, tais como a social, a cultural, a política (nacionais e internacionais), a econômica, a ambiental entre outras. E a reflexão sobre essas (outras) dimensões muda os rumos das discussões sobre sustentabilidade.

Esse fato decorre da necessidade de compreender, buscar, viabilizar e implementar um processo de desenvolvimento que considere a tríade mínima da sustentabilidade, qual seja: a eficiência econômica, a justiça social e a qualidade ambiental (VEIGA, 2003), com urgência, inclusive, para a presente geração. Nessa linha de pensamento, Acselrad(1999) já afirmavaque a noção de sustentabilidade sempre estará submetida à lógica das práticas, e a sustentabilidadesó poderá ser alcançada quando for considerada a relação dos problemas socioambientais com as práticas cotidianas da sociedade.De fato, até hoje a concepção de sustentabilidade sempre gera expectativas quanto à transformação de hábitos $\mathrm{e}$ de experiências que possam ser suportados pelaambiência social e ambiental, o que foi anunciada, prospectivamente, pelo autor supracitado.

É importante lembrar que não existe um conceito firmemente estabelecido de sustentabilidade, que explique todos os seus sentidos, finalidades e dimensões. Entretanto, para compreender mais sobre essa ideia podemos relacioná-la a alguns conceitos biológicos, como, por exemplo, a capacidade de suporte natural, que é bastante discutido no âmbito da ecologia. Segundo Ricklefs (2010), a capacidade de suporte consiste na condição da existência de que, em um dado ecossistema, se percebam as características necessárias para a sustentação das necessidades básicas (elementos/recursos) e de sobrevivência dos seres vivos que o constituem, de modo que ele possa ser recuperado naturalmente.

Nesse raciocínio, para alguns cientistas, a humanidade pode estar em um momento muito delicado de sua história, haja vista que existem teorias em que se defende que as ações antrópicas podem estar ultrapassando a capacidade de suporte do planeta (VEIGA, 2005). Inclusive, já se fala do "[...] Antropoceno como unnuevo período geológico, marcado por elhecho de que los grandes cambiosenel planeta - y, muy concretamente, enla biosferasondebidos a laacción humana" (VILCHES; GIL PÉREZ, 2011, p. 394). É evidente que o 
desenvolvimento causa a depleção de recursos naturais e, consequentemente, promove, em médio e longo prazos, a diminuição e até o empobrecimento desses recursos (VEIGA, 2005; RICKLEFS, 2010). Por isso, durante os processos que envolvem o desenvolvimento é necessário compreender os elementos e as condições que garantam a sustentação do sistema Terra.

Em verdade, apesar das interessantes reflexões que o entendimento da dinâmica dos ecossistemas possa gerar, elas não são suficientes para compreendermos a situação planetária atual. Isso porque, segundo Fenzel (2011), nem a crise socioambiental e tampouco a sustentabilidade do planeta está condicionada pela capacidade de suporte natural da Terra - o principal problema socioambiental a ser enfrentado, hoje, refere-se à especulação econômica, altamente concentradora de renda engendrada no âmbito capitalista.Problemas como a fome, por exemplo, não estão relacionados à incapacidade da Terra fornecer alimentos para os seus mais de sete bilhões de habitantes, mas sim aos mecanismos de produção e distribuição igualitário desses alimentos na sociedade (FENZEL, 2011). Todavia, o conceito de capacidade de suporte pode ser muito bem aplicado, quando estudado em relação a uma das problemáticas gerada pelo desenvolvimento, o consumo desenfreado. Porquanto, o modo de crescimento econômico ligado ao consumo rápido e desmesurado leva ao esgotamento de recursos e à incapacidade de reciclagem natural de detritos pelo meio ambiente (RICKLEFS, 2010; VEIGA, 2005).

Zanetti, Sá e Almeida (2009, p. 177) afirmam que, na lógica do consumo, como mola propulsora da produtividade do sistema econômico vigente, os bens de consumo duráveis devem ser aniquilados, pois o "[...] encurtamento deliberado da vida útil das mercadorias possibilita o lançamento de um contínuo suprimento de mercadorias super produzidas no vórtice da circulação que se acelera”. Desse modo, estimula-se a substituição do novo, por outro mais novo ainda, sob a justificativa da inovação tecnológica e da expansão de um mercado de massas e do supérfluo. Para Barbieri (2010, p. 148), “[...]há quem entenda que o crescimento econômico é a origem dos graves problemas ambientais e sociais observados no mundo contemporâneo". Tal pensamento se coaduna com a discussão anteriormente realizada, pois o crescimento econômico, na atualidade, é incrementado pelo o consumo e, por vezes, pela incitação ao consumismo. Por isso, qualquer ideia que pretenda a transformação do cenário atual precisa passar por uma reorientação dos processos econômicos.

Sendo assim, se o modelo de desenvolvimento atual não for substituído por outro, que seja naturalmente sustentável e autossustentado, o caos ambiental global se tornará um futuro 
esperado. Em vista disso, devemos imprimir a transição da condição de insustentabilidade dos processos de desenvolvimento para aquela de sustentabilidade. Em realidade, o crescimento econômico constitui-se condição necessária, porém não suficiente para o desenvolvimento (SACHS, 2005). Nesse sentido, defendemos que, uma vez esclarecida por conhecimentos socialmente construídos, inclusive os científicos, a população geral poderá compreender sua realidade e construir várias maneiras de garantir o bem-estar social, fundados no pressuposto fundamental da sustentabilidade. Nesse ponto, destacamos que as discussões sobre o desenvolvimento sustentável se ampliaram no decorrer dos anos. Isso porque

O conceito de desenvolvimento sustentável [...] passou a englobar quatro dimensões básicas: a ética, que envolve a solidariedade em relação às futuras gerações; a temporal, através da precaução e planejamento em longo prazo; a social, pela diminuição das desigualdades; e a prática, que reconhece como necessária a mudança de hábitos de consumo e de comportamentos (ZOTTIS et al., 2008. p. $35)$.

Apesar de essas mudanças estarem presentes nas discussões teóricas mais recentes sobre desenvolvimento sustentável, ainda se percebe que a ênfase nas dimensões ética e prática é ofuscada por dimensões tradicionalmente colocadas, a saber,a dimensão econômica e a ecológica. Talvez, esse seja um dos principais motivos que tem impedido a concretização da ideia da sustentabilidade.

Diante do exposto, a emergência das discussões sobre sustentabilidade se deu na medida em que se ampliou o entendimento acerca do fato de a humanidade estar impactando o meio ambiente, de tal modo que a capacidade de suporte dos sistemas naturais e sociais está sendo desestabilizada. Esse destaque atribuído à sustentabilidade, nos dias de hoje, confirmanos a necessidade de mudança de pensamento, práticas e hábitos citados por Acselrad(1999). Isso no sentido de favorecer a construção de um desenvolvimento sustentável, o que até hoje é considerado um mito, mas, por outro lado, representa uma visão de futuro, sobre a qual a humanidade precisa fundamentar seus objetivos (VEIGA, 2005).

Nesse sentido, Jacobi (2003b, p. 194-195)afirma que a “[...] noção de desenvolvimento sustentável leva à necessária redefinição das relações sociedade humana/natureza e, portanto, a uma mudança substancial do próprio processo civilizatório". Assim, o desenvolvimento sustentável é, impreterivelmente, um assunto que trata da relação entre pessoas, e destas com o meio em que vivem e convivem. Nessa nova concepção de desenvolvimento, o ser humano é reconhecido e fundamental para o sucesso do processo. Cabe destacar que as relações que buscam o interesse unicamente econômico não são mais 
indicadas para esse novo século.Nesse contexto, priorizar o entendimento da sustentabilidade durante o ensino de ciências é fundamental.

\section{O PARADIGMA DA SUSTENTABILIDADE E ENFOQUE CTS: CONTRIBUIÇÕES PARA O ENSINO DE CIÊNCIAS}

Em nossa compreensão, para realizar um ensino de ciências que focalize a sustentabilidade em interação com a perspectiva CTS, é necessário apresentar as articulações possíveis. Destacamos, para fins deste trabalho, dois grandes eixos, quais sejam: a educação científica e a interdisciplinar. Para isso, elencamos e analisamos quatro pontos em comum, que julgamos interessantes para ambos os eixos, são eles: 1) cidadania, 2)tomada de decisão, 3) contextualização (que também se reporta às preocupações com os interesses e potencialidades locais), e 4) compreensão das implicações das construções científica e tecnológica no âmbito da sociedade.

Se refletirmos sobre as discussões apresentadas neste artigo, é compreensível que uma formação para cidadania contemple os objetivos do enfoque CTS no ensino de ciências, bem como da noção de sustentabilidade, haja vista que a cidadania responsável habilita os sujeitos para interagirem com problemas científicos e tecnológicos que influenciam a dinâmica social. Nesse âmbito, o ensino e a aprendizagem de ciências colaboram com a construção da capacidade de expressão articulada, a partir do desenvolvimento das estruturas intelectuais e cognitivas (VIEIRA; VIEIRA, 2005; JACOBI, 2003a).

Nesse campo (cidadania), a participação social constitui-se fator fundamental para o alcance da democracia. A Conferência Mundial sobre a Ciência, realizada em Budapeste, em 1999, já fazia referência à importância da educação científica como pré-requisito fundamental da democracia e para o desenvolvimento sustentável (UNESCO, 2003). Nesse ponto, corroboramos com Demo (2001), quando afirma que participação é conquista. Entendemos que se trata de conquistas vinculadas ao direito à saúde, à educação, ao trabalho, à alimentação, à cultura, à diversidade, à paz, a um ambiente ecologicamente saudável, entre tantos outros. Além disso, todos os aspectos arrolados são pertinentes a uma ou mais dimensões da sustentabilidade. 
Por sua vez, a tomada de decisão implica na participação dos cidadãos na elaboração, aplicação e crítica dos processos sociais, notadamente aqueles que envolvem o desenvolvimento, a sustentabilidade e a qualidade de vida da população. Porquanto, a participação efetiva dos cidadãos na tomada de decisão é compreendida como um fator positivo quando fundamentada em conhecimentos e argumentos bem articulados a conhecimentos científicos e a um olhar crítico sobre a realidade (FIRME; AMARAL, 2008; CACHAPUZ, 2005). Ademais, a tomada de decisão colabora para a constituição de cenários democráticos no contexto da sala de aula.

A educação científica pode trazer à cena da sala de aula temas próprios ao contexto social, como, por exemplo, a fome, a violência, as desigualdades sociais e os aspectos da sustentabilidade, os quais podem ser vinculados às implicações do desenvolvimento e sua estreita relação com o paradigma econômico dominante, em detrimento de outros tão importantes para a sociedade. Entendemos que esse é um fator relevante para propiciar uma educação científica que habilite os cidadãos para a tomada de decisão. Isso porque o entendimento da realidade leva à consideração das necessidades, dos problemas e das expectativas das pessoas e da coletividade em múltiplos aspectos e espaços. A contextualização, além de propiciar o (re) conhecimento da realidade circundante, manifesta o respeito pela diversidade cultural e o compromisso de criar local e globalmente uma cultura de tolerância e de paz (PINHEIRO; SILVEIRA; BAZZO, 2007; CACHAPUZ, 2005; TEIXEIRA, 2003).

Outro ponto importante de inflexão, na articulação da noção de sustentabilidade e o enfoque CTS,diz respeito à compreensão das implicações sociais decorrentes das construções científicas e tecnológicas. Como observamos no decorrer deste artigo, as questões socioambientais estão quase sempre relacionadas à forma como a humanidade compreende e utiliza a ciência e a tecnologia. Diante da complexidade dos eventos que constituem a dinâmica social, torna-se necessário refletirmos mais sobre a história do conhecimento científico, sobre a forma como este se estabeleceu e como se tornou um condicionante para o desenvolvimento tecnológico, econômico e social.

Nesse ponto, podemos referir que a interdisciplinaridade é um caminho inevitável para a construção da noção de sustentabilidade. Porquanto, para a realização de um ensino de ciências que dê conta de esclarecer o cenário atual, uma só disciplina ou disciplinas compartimentadas não serão suficientes. Em nossa compreensão, a interdisciplinaridade consiste na relação das diversas áreas do conhecimento para permitir uma compreensão mais 
aprofundada e global de uma dada questão. Nesse sentido, a articulação das produções científicas de diversas áreas (Física, Biologia, Química, Economia, Sociologia, Filosofia, entre outras) pode possibilitar profundas reflexões sobre o atual estágio do processo de desenvolvimento (VEIGA, 2005; CACHAPUZ; PRAIA; JORGE, 2004; BRASIL, 1999).

Por outro lado, temos que assumir, como professores, uma nova postura epistemológica. Trata-se, nos termos de Amaral (2007), de deslocar o aluno do lugar de mero espectador dos fatos para a cena do cidadão ativo - aquele que pode refletir e propor soluções para problemas vigentes na sociedade. E, nesse contexto, depreendemos que as metodologias centradas no aluno constituem-se, no conjunto, ferramenta própria para tornar o espaço de sala de aula impregnado pelo protagonismo discente e diálogo coletivo.

\section{CONSIDERAÇÕES FINAIS}

O ensino de ciências tem se ocupado com múltiplos desafios que são postos hoje para a sociedade. Em realidade, as sociedades são confrontadas cotidianamente com questões que envolvem as interações entre Ciência, Tecnologia e Sociedade (CTS). Em tais interações, estão implicados aspectos sociais, econômicos, ambientais éticas, entre outros. É bem verdade que o avanço da ciência e da tecnologia colabora para a melhoria das condições de vida de uma parcela da sociedade. É justamente esse último aspecto que permite problematizar as relações CTS no ensino de ciências.

A articulação entre o paradigma da sustentabilidade e o enfoque CTS, no âmbito do ensino de ciências, é possível e desejável. Temos atestado, por meio das nossas próprias vivências na prática docente, que isso é plenamente plausível. Portanto, não se trata de uma mera possibilidade prospectiva. Essa articulação, certamente, contribui para pensar as implicações do atual modelo de desenvolvimento e as relações CTS, situadas em vários temas, contextos, dimensões, saberes e estratégias de ensino, entre outros aspectos.

Por seu turno, essa articulação possibilita ponderar sobre a construção de um modelo de desenvolvimento alternativo ao que hoje experimentamos, mediante processo de questionamentos e reflexões, na melhor compreensão das questões implicadas nas relações CTS e seus desdobramentos para o próprio processo de desenvolvimento, agora pensado sob a 
premissa da sustentabilidade. Destacamos que a compreensão da história, do cotidiano e dos fundamentos científicos é essencial para esse processo.

Diante da crise ambiental vigente, entendemos como necessário que o ensino de ciências ofereça condições para que os estudantes possam conhecer e apreender conceitos transversais. Precisamente, aqueles relativos à ética, à justiça social, à participação democrática, aos processos de desenvolvimento (e suas múltiplas dimensões), à equidade e à justiça ambiental, à cidadania, ao meio ambiente, de modo que os habilitem a entender a atual realidade ambiente e favorecer o posicionamento consubstanciado frente às questões postas.Certamente, as discussões permeadas pela perspectiva CTS colocarão em relevo a questão da sustentabilidade

A formação dos professores, inicial e continuada, não pode ser esquecida nessa discussão, pois é o professor quem articula informações e conhecimentos no processo de ensino e de aprendizagem. E, por conseguinte,o professor não pode ensinar ou discutir o que não conhece, referimo-nos, especificamente, às questões do desenvolvimento, da sustentabilidade e das relações CTS. Nesse âmbito, a EDS em muito colaborará, uma vez que compreende a sustentabilidade como horizonte, uma prática que deve ser buscada cotidianamente. Entendemos que as questões socioambientais não podem ser apreendidas e compreendidas por uma abordagem disciplinar - necessitam pautar-se pela complexidade dos processos que a conformam, sem o que toda e qualquer ação, neste âmbito, apresentar-se-á inócua, asséptica. Portanto, de pronto, percebemos que não se trata de qualquer formação, mas, sim, aquela que privilegia abordagem sistêmica e integral, orientada para favorecer uma adequada percepção dos problemas socioambientais vigentes, além de favorecer a formação de um cidadão crítico, autônomo, criativo, capaz de compreender a complexidade do mundo natural e social e, assim, presumivelmente, preparado para o enfrentamento das incertezas e da tomada de decisões.

$\mathrm{Na}$ formação em EDS, considerando que a conformação do desenvolvimento sustentável está ligada à apreensão das interações CTS, faz-se necessário favorecer a compreensão crítica das questões socioambientais contemporâneas, além de estabelecer conteúdos que permeiam discussões e discursos de sustentabilidade, notadamente no que tange aos seguintes aspectos: argumentações, pressupostos, valores, interesses, objetivos, posicionamento ético e político e contradições, entre outros, os quais representam, no conjunto, um processo que busca imprimir uma educação científica para o desenvolvimento sustentável. De certo, as vivências de aprendizagem, nesse campo, devem alicerçar-se em 
múltiplas possibilidades metodológicas, centradas, preferencialmente, nos sujeitos aprendentes e em cenários reais.

Temos que refletir e questionar sobre os sentidos, os significados e as implicações da relação que se estabelece entre o ensino de ciências e o desenvolvimento sustentável. Também é de fundamental importância, nesse processo, compreender e problematizar os limites que se interpõem à postura crítica e analítica dos professores em processo de formação, inicial ou continuada, frente aos aspectos que envolvem a (in) sustentabilidade do planeta, na construção de um futuro sustentável, dado o seu papel destacado na constituição de cidadãos críticos, capazes de tomada de decisão, consoante com os interesses de conformação de sociedades sustentáveis. Certamente, temos que empreender no esforço de aproximar o campo natural e o campo social, na apreensão da complexa realidade que hoje se apresenta.

\section{REFERÊNCIAS}

ACSELRAD, H. Discursos da sustentabilidade urbana. Revista Brasileira Estudos Urbanos e Regionais, Campinas, v.1, n.1,p. 79-90, 1999.

AMARAL, Marta Teixeira do. A dimensão ambiental na cultura educacional brasileira. Revista Brasileira de Estudos Pedagógicos. Brasília, v. 88, n. 218. p. 107-121, 2007.

AULER, D. Interações entre Ciência-Tecnologia-Sociedade no Contexto da Formaçãode Professores de Ciências. 250 f. Tese (Doutorado). Programa de Pós-Graduação em Educação. Universidade de Santa Catarina. Santa Catarina, 2002.

.; DELIZOICOV, D. Alfabetização científico-tecnológico para quê? Ensaio: Pesquisa em Educação em Ciências, Campinas, v. 3, n.1, p.105-115, 2001.

BAZZO, W. A. Ciência, tecnologia e sociedade e o contexto da educação tecnológica. Florianópolis: UFSC, 2010. 287 p.

BARBIERI, C. J. et al. Inovação e sustentabilidade: novos modelos e proposições. $R A E$, São Paulo, v. 50, n. 2, p. 146-154, 2010.

BIGLIARDI, R. V.; CRUZ, R. G. O papel da educação ambiental frente á crise civilizatória atual. Ambiente \& Educação, Rio Grande, v. 12, p. 127-141, 2007. 
BRASIL, Ministério da Educação. Secretária de Educação Média e Tecnológica. Parâmetros curriculares nacionais: ensino médio. Brasília: Secretária de Educação Média e Tecnológica, 1999. $364 \mathrm{p}$.

CACHAPUZ, A. et al. A necessária renovação no ensino das ciências. São Paulo: Cortez, 2005. 263 p.

; PRAIA, J; JORGE, M. Da educação em ciência às orientações para o ensino das ciências: um repensar epistemológico. Ciência\&Educação, Bauru,v. 10, n. 3, p. 363-381, 2004.

CARSON, Rachel. Primavera silenciosa. São Paulo: Gaia, 2010. 327 p.

CASSIANI, S; LINSINGEN, I. V. Formação inicial de professores de ciências: perspectiva discursiva na educação CTS. Educar, Curitiba, n. 34, p. 127-147, 2009.

DELIZOICOV, D; ANGOTTI, J. A; PERNAMBUCO, M. M. Ensino de ciências fundamentos $e$ métodos. 3. ed. São Paulo: Cortez, 2009. 364 p

DEMO, P. Participação é conquista: noções de política social participativa. São Paulo: Cortez, 2001. $176 \mathrm{p}$.

FENZEL, Entrevista a TV Cultura. Programa Roda-Viva da TV Cultura: 2011

FIRME, R. N.; AMARAL, E. M. R. Concepções de professores de química sobre ciência, tecnologia, sociedade e suas inter-relações: um estudo preliminar para o desenvolvimento de abordagens CTS em sala de aula. Ciência\&Educação, Bauru, v. 14, n. 2,p. 251-269, 2008.

JACOBI, Pedro. Educação ambiental, cidadania e sustentabilidade.Cadernos de Pesquisa, São Paulo, n.118, p. 189-206, 2003a.

Espaços públicos e práticas participativas na gestão do meio ambiente no Brasil. Sociedade e Estado, Brasília, v. 18, n. 1/2, p. 137-154, 2003 b.

JATOBÁ, S. U. S; CIDADE, L. C. F; VARGAS, G. M. Ecologismo, ambientalismo e ecologia política: diferentes visões da sustentabilidade e do território. Sociedade e Estado, Brasília, v. 24, n. 1, p. 47-87, 2009.

KUHN, T. A Estrutura das Revoluções Científicas. 10 ed. São Paulo: Perspectiva, 2010. 264 p.

LEAR, Linda. Introdução. In: CARSON, Rachel. Primavera silenciosa. São Paulo: Gaia, 2010. p. 1119. 
LEFF, Enrique. Epistemologia ambiental. 2 ed. São Paulo: Cortez, 2002. 24 p.

LINSINGEN, I. Perspectiva educacional CTS: aspectos de um campo em consolidação na América Latina. Ciência \& Educação, Bauru, v. 1, número especial, 2007.

LOUREIRO, C. F. B.Trajetórias e fundamentos da educação ambiental. $3^{\mathrm{a}}$ ed. São Paulo: Cortez, 2009. $150 \mathrm{p}$.

MUENCHEN, C; AULER, A. Configurações curriculares mediante o enfoque CTS: desafios a serem enfrentados na educação de jovens e adultos. Ciência \& Educação, Bauru, v. 13, n. 3, p. 421-434, 2007.

PINHEIRO, N. A. M; SILVEIRA, R. M. C. F; BAZZO, W. A. Ciência, tecnologia e sociedade:a relevância do enfoque CTS para o contexto do ensino médio. Ciência \& Educação, Bauru,v. 13, n. 1, p. 71-84, 2007.

; ___ $\quad$ _ O contexto científico-tecnológico e social acerca de uma abordagem críticoreflexiva: perspectiva e enfoque. Revista Iberoamericana de Educación, España, n. 49/1, 2009

RICKLEFS, R. E. A Economia da Natureza. 6 ed. Rio de Janeiro: Guanabara Koogan, 2010. 570 p.

SANTOS, Wilson Luiz Pereira dos. Significados da educação científica com enfoque CTS. In: _ _ AULER, Décio.CTS e educação científica: desafios, tendências e resultados de pesquisas. Brasília: UNB, 2011. p. 21-47.

SILVEIRA, R. M. C. F. BAZZO, W. A. Ciência, tecnologia e suas relações sociais: a percepção de geradores de tecnologia e suas implicações na educação tecnológica. Ciência \& Educação, Bauru, v. 15, n. 3, p. 681-694, 2009.

SACHS, I. Desenvolvimento: includente, sustentável, sustentado. Rio de Janeiro: Garamond, 2008. $151 \mathrm{p}$.

Prefácio. In: VEIGA, José Eli da.Desenvolvimento sustentável: o desafio do século XXI. Rio de Janeiro: Garamond, 2005. p. 9-11.

SHOR, T. Reflexões sobre a imbricação entre ciência, tecnologia e sociedade. ScientičZudia, São Paulo, v. 5, n. 3, p. 337-67, 2007.

TEIXEIRA, P. M.A educação científica sob a perspectiva da pedagogia histórico-crítica e do movimento CTS no ensino de ciências. Ciência \& Educação, Bauru, v. 9, n. 2, p. 177-190, 2003. 
UNESCO. A ciência para o século XXI: uma nova visão e uma base de ação. Brasília: UNESCO, ABIPTI, 2003. $72 \mathrm{p}$.

VEIGA, J. E. Cidades imaginárias. Rio de Janeiro: Autores Associados, 2003. 305 p.

Desenvolvimento sustentável: o desafio do século XXI. Rio de Janeiro: Garamond, 2005. 226

p.

VIEIRA, C. T.; VIEIRA, R. M. Construção de práticas didático-pedagógicas com orientação CTS: impacto de um programa de informação continuada de professores de ciências do ensino básico. Ciência \& Educação, Bauru, v.11, n. 2, p. 191-211, 2005.

VILCHES, A.; GIL PÉREZ, D.; PRAIA, D. De CTS a CTSA: educação por um futuro sustentável. In: SANTOS, W. L. P. dos; AULER, D. CTS e educação científica: desafios, tendências e resultados de pesquisas. Brasília: UNB, 2011. p.161-184.

ZANETTI, I. C. B. B,; SÁ, L. M.; ALMEIDA, V. G. Insustentabilidade e produção de resíduos: a face oculta do sistema do capital. Sociedade e Estado, Brasília, v. 24, n. 1, p. 173-19, 2009.

ZOTTIS, H. G. A.et al. Violência e desenvolvimento sustentável: o papel da Universidade. Saúde e Sociedade, São Paulo, v.17, n.3, p.33-41, 2008.

WILSON, E. O posfácio.In: CARSON, Rachel. Primavera silenciosa.São Paulo: Gaia, 2010. p. 250256. 